\title{
Nulidad Electoral:
}

\section{Límite a la aplicabilidad del principio non bis in ídem}

\author{
Electoral nullity: Limit to the applicability of the principle non bis in idem
}

Martha PATricia Tovar Pescador ${ }^{1}$

$2^{\circ}$ lUS Comitiâlis / Año 4, Número 7 / enero - junio 2021 / pp. 265-290 / ISSN: 2594-1356

Recepción: 8 de enero del 2021 / Aceptación: 13 de abril de 2021

\section{(c) (1) $(9)$}

Esta obra está bajo licencia Creative Commons

Attribution-NonCommercial-ShareAlike $\quad 4.0$

International (CC BY-NC-SA 4.0)

Resumen: Mediante el uso de los métodos analítico y comparativo, puede estudiarse la existencia de violaciones al principio non bis in ídem establecido en el artículo 23 de la Constitución Política de los Estados Unidos Mexicanos, derivado de conductas que actualizan, por una parte, infracciones a la normativa político-electoral dentro del régimen administrativo sancionador electoral y, por otra parte, infracciones que pueden constituir una causal de nulidad de elecciones. Se plantea un estudio de caso para discutir la existencia de violaciones a este principio al examinar las teorías que conforman el cuerpo teórico sobre los elementos configuradores del mismo. Por último, se realiza un estudio comparativo de la forma en que España observa este problema en la resolución de conflictos.

Palabras clave: Non bis in ídem, Sanción, Delito, Infracciones, Nulidades Electorales.

Abstract: Through the use of analytical and comparative methods, the existence of violations of the non bis in idem principle enshrined in article 23 of the Political Constitution of the United Mexican States can be studied, derived from conducts that update, on the one hand, infractions to the political-electoral regulations within the electoral sanctioning administrative regime; and, on the other hand, infractions that may constitute a cause for the nullity of elections. A case study is proposed to discuss the existence of violations of this principle, when examining the theories that make up the theoretical body on its shaping elements. Finally, a comparative study is carried out on the way in which Spain observes this problem in conflict resolution.

Key words: Non bis in idem, Sanction, Crime, Offenses, Electoral Nullities.

https://orcid.org/0000-0002-8833-2207. / Correo electrónico: topes_mar@hotmail.com

${ }^{1}$ Instituto Electoral del Estado de México. Centro de Formación y Documentación Electoral, Toluca, Estado de México, México. 


\section{INTRODUCCIÓN}

El 24 de agosto del año 2015, la Sala Regional del Tribunal Electoral del Poder Judicial de la Federación (TEPJF), correspondiente a la Quinta Circunscripción Plurinominal, con sede en la ciudad de Toluca, Estado de México, al resolver el expediente ST-JRC-206/2015, declaró la nulidad de la elección de miembros del ayuntamiento de Sahuayo, en el Estado de Michoacán, debido a que el presidente municipal desvió recursos públicos municipales a través de un equipo de fútbol a favor del candidato postulado por el Partido Acción Nacional, quien el día que se celebró la jornada electoral resultó ser el ganador de la contienda electoral. El fundamento para declarar la nulidad de aquella elección fue el artículo 41, base VI, inciso c) de la Constitución Política de los Estados Unidos Mexicanos, que prohíbe el desvío de recursos públicos.

De forma ulterior, el 23 de noviembre de 2016, el Consejo General del Instituto Electoral de Michoacán resolvió sobreseer el Procedimiento Ordinario Sancionador identificado con el número de expediente IEM-PA-36/2015, del cual tuvo conocimiento 18 meses previos, puesto que la denuncia fue presentada ante dicha autoridad, el 12 de mayo de 2015, ya que consideró que el fondo de la controversia había sido resuelto por la Sala Toluca del TEPJF al declarar la nulidad de la elección de miembros del ayuntamiento de Sahuayo en el expediente ST-JRC-206/2015, por lo que se actualizaba el principio contenido en el artículo 23 de la Constitución Política de los Estados Unidos Mexicanos, consistente en que "nadie puede ser juzgado dos veces por el mismo delito”, también conocido como non bis in ídem.

De tal manera que el presente artículo tiene como finalidad identificar en qué consiste el principio non bis in ídem, aludido por el Instituto Electoral de Michoacán, cuáles han sido los criterios emitidos por la Suprema Corte de Justicia de la Nación (SCJN) y los órganos del Poder Judicial de la Federación con relación a este, así como las figuras jurídicas que surgen a su alrededor, para determinar si tal principio protege a la persona que ha ocasionado la nulidad de una elección, para no ser sancionado bajo el régimen de administrativo sancionador electoral.

\section{EL PRINCIPIO NON BIS IN IDEM Y SU RECONOCIMIENTO EN LA CONSTITUCIÓN POLÍTICA DE LOS ESTADOS UNIDOS MEXICANOS}

La primera vez que se introdujo el principio non bis in ídem en nuestro ordenamiento jurídico fue en la Constitución de 1857, específicamente en el artículo 24, el cual establecía:

Ningún juicio criminal puede tener mas de tres instancias. Nadie puede ser 
juzgado dos veces por el mismo delito, ya sea que en el juicio se le absuelva ó se le condene. Queda abolida la práctica de absolver de la instancia (sic).

Al promulgarse la Constitución de 1917, hasta hoy vigente, el principio en análisis quedó comprendido en el artículo 23, conservando la misma redacción. Por su parte, Haro (2012) afirma que gran parte de la doctrina mexicana coincide en que la redacción y traducción del hoy artículo 23 constitucional fue un plagio de la quinta enmienda a la Constitución Política de los Estados Unidos de Norteamérica (p. 22), la cual indica:

Fifth Amendment. No person shall be held to answer for a capital, or otherwise infamous crime, unless on a presentment or indictment of a Grand Jury, except in cases arising in the land or naval forces, or in the Militia, when in actual service in time of War or public danger; nor shall any person be subject for the same offence to be twice put in jeopardy of life or limb; nor shall be compelled in any criminal case to be a witness against himself, nor be deprived of life, liberty, or property, without due process of law; nor shall private property be taken for public use, without just compensation $^{2}$.

Pareciera que la simple lectura del artículo 23 de la Constitución vigente basta para entenderlo: "nadie puede ser juzgado dos veces por el mismo delito". Sin embargo, tal principio tiene muchas más consecuencias en la vida jurídica, como se expondrán en los párrafos siguientes.

En primer lugar, es importante destacar que la traducción al español del término offense, referido en la quinta enmienda, fue retomada con el término de delito en las constituciones mexicanas del 1857 y 1917, restringiendo su aplicación al ámbito penal. Como consecuencia de ello, el constituyente de 1856 no pudo hacer una diferencia entre averiguaciones y juicio, porque en esa época correspondía a los jueces investigar y sancionar los delitos, es decir, el juez penal investigaba el hecho tipificado como delito e imponía la pena correspondiente (Haro, 2012, p. 23). No obstante, cuando se promulgó la constitución de 1917 ningún constituyente identificó que en el artículo 102 del mismo ordenamiento se determinó como competencia del Ministerio Público de la Federación:

\footnotetext{
2 "Nadie estará obligado a responder de un delito castigado con la pena capital o con otra infamante si un gran jurado no lo denuncia o acusa, a excepción de los casos que se presenten en las fuerzas de mar o tierra o en la milicia nacional cuando se encuentre en servicio efectivo en tiempo de guerra o peligro público; tampoco se pondrá a persona alguna dos veces en peligro de perder la vida o algún miembro con motivo del mismo delito; ni se le forzará a declarar contra sí misma en ningún juicio criminal; ni se le privará de la vida, la libertad o la propiedad sin el debido proceso legal; ni se ocupará su propiedad privada para uso público sin una justa indemnización” (énfasis añadido por la autora).

${ }^{3}$ Habrá que recordar que el texto original de la Constitución establecía en su artículo 73 fracción VI como facultad del Congreso de la Unión, legislar en todo lo relativo al Distrito Federal y Territorios, estableciéndose en el ordinal $5^{\circ}$ : El Ministerio Público en el Distrito Federal y en los Territorios estará a cargo de un Procurador General, que residirá en la Ciudad de México, y del número de agentes que determine la ley, dependiendo dicho funcionario directamente del Presidente de la República, quien lo nombrará y removerá libremente.
} 
...la persecución, ante los tribunales, de todos los delitos del orden federal; y, por lo mismo, a él le corresponderá solicitar las órdenes de aprehensión contra los reos; buscar y presentar las pruebas que acrediten la responsabilidad de éstos; hacer que los juicios se sigan con toda regularidad para que la administración de justicia sea pronta y expedita; pedir la aplicación de las penas e intervenir en todos los negocios que la misma ley determinare.

Es decir, la nueva constitución preveía en favor del ministerio público la competencia para investigar los delitos, en tanto que el juez penal era competente para enjuiciar al imputado. Por ello, a decir de Haro (2012), la expresión offense debió ser redactada como hechos, para que el principio protegiera no sólo las conductas consideradas como delitos, sino que también quedaran incluidas las infracciones administrativas (p. 23) y con ello ampliar la protección del principio en análisis a todo tipo de conducta y sanciones, ya fueran penales o administrativas. Cogan Neil, en The Complete Bill of Rights: The Drafts, Debates, Sources, and Origins, con base en los debates previos a la aprobación de la quinta enmienda, sostiene que los congresistas norteamericanos tenían como objetivo señalar que nadie pudiera ser sometido a un procedimiento o proceso más de una vez y, en consecuencia, que tampoco pudiera ser sancionado más de una vez por los hechos correspondientes (p.19).

Sobre este contexto, resulta de vital trascendencia señalar que si se ha aceptado desde las resoluciones de los diversos tribunales administrativos la aplicación del principio non bis in ídem en este tipo de procedimientos, no fue sino hasta 1997 -es decir, 80 años después de que entró en vigor la constitución de 1917- que el Pleno de la Suprema Corte de Justicia de la Nación (SCJN) aceptó de manera obligatoria su protección a través de la jurisprudencia intitulada: "Sentencias de nulidad fiscal para efectos. El artículo 239, fracción III, último párrafo, del Código Fiscal de la Federación, que las establece, no es violatorio de la garantía de seguridad jurídica prevista en el artículo 23 constitucional" (Jurisprudencia P./J.84/97 de 3 de noviembre de 1997). Respecto de la décima época, sólo el Primer Tribunal Colegiado de Circuito en Materia Administrativa Especializado en Competencia Económica, Radiodifusión y Telecomunicaciones, con residencia en el entonces Distrito Federal ${ }^{4}$ y Jurisdicción en toda la República, ha aceptado de manera expresa la protección del principio en análisis en la materia administrativa, al aprobar la tesis: "Non bis in ídem. Este principio es aplicable, por extensión, al derecho administrativo sancionador" (Tesis I.1o.A.E.3 CS (10a.) de 29 de abril de 2016). Así, aún cuando el artículo 23 constitucional establece expresamente un ámbito de aplicación penal para el principio non bis in ídem, de la interpretación que han realizado la SCJN y los Tribunales Colegiados de Circuito, se amplía su rango de protección para el efecto que aplique también respecto del ámbito administrativo.

\footnotetext{
${ }^{4}$ Con motivo de la reforma constitucional de 29 de enero de 2016, la entrada en vigor de la Constiutción Politica de la Ciudad de México publicada el 5 de febrero de 2017 y del Acuerdo General del Pleno del Consejo de la Judicatura Federal por el que se cambia la denominación de Distrito Federal por Ciudad de México en todo su cuerpo normativo, la denominación actual del órgano emisor es la de Primer Tribunal Colegiado de Circuito en Materia Administrativa Especializado en Competencia Económica, Radiodifusión y Telecomunicaciones, con residencia en la Ciudad de México y jurisdicción en toda la República.
} 
Definido el ámbito de aplicación, es necesario establecer sus alcances. Al respecto, Cárdenas Rioseco (2005) señala que la definición de nuestra constitución es restringida (p. 7), puesto que únicamente hace alusión a un aspecto material que impide al juzgador dictar dos sentencias - ya sea de absolución o de condena - por un mismo hecho [ilícito]; no obstante, el mismo autor reconoce que, desde la doctrina, el principio en análisis tiene un alcance mucho mayor, en virtud de que también impide la múltiple persecución penal como garantía de seguridad del inculpado, al que denomina, siguiendo a J. B. J. MAIER, un sentido procesal, que cubre el "riesgo" de una persecución penal renovada cuando ha fenecido una anterior o aún esté en trámite (p. 8). En el mismo sentido, Haro (2012) señala que el principio en referencia tiene dos modalidades, una sustantiva o material consistente en que nadie debe ser castigado dos veces por la misma conducta, esto es, que no se impongan o atribuyan dos sanciones a una misma conducta; y otra adjetiva o procesal consistente en que nadie debe ser juzgado dos veces por el mismo hecho, siempre que sobre el mismo haya recaído sentencia firme -de absolución o condena-, auto de sobreseimiento o confirmación del no ejercicio de la acción penal (p. 26-27). Esto es, los autores en consulta distinguen dos vertientes del principio non bis in ídem, en un primer momento, la interpretación restringida, sustantiva o material, en la que se establece que nadie puede ser sancionado o castigado dos veces por el mismo delito, esta vertiente protege a la persona de la condena, es decir, que a ningún ciudadano se le pueda imponer más de una sanción o pena por los mismos hechos. La segunda vertiente amplia, procesal o adjetiva tiene como fin impedir que el Estado persiga o inicie un procedimiento en más de una ocasión por los mismos hechos. Con ello, la vertiente procesal protege el fin último previsto por el principio non bis in ídem, que es la prohibición de iniciar un segundo proceso cuando el hecho que lo motivó ya ha sido materia de uno previo. En cuanto a la interpretación de estas dos vertientes, la restringida, sustantiva o material está plenamente garantizada por los Tribunales del Poder Judicial de la Federación desde su implementación en la Constitución, en tanto que la relacionada con la amplia, procesal o adjetiva ha tenido una evolución en su aplicación, como a continuación se demostrará:

La Primera Sala de la SCJN, al resolver el amparo en revisión 6856/39, indicó que el principio non bis in ídem previene que "un individuo juzgado por un delito no pueda serlo de nuevo por los mismos hechos que han sido materia de la acusación anterior, pero siempre que en esta se haya dictado la absolución o la condenación del enjuiciamiento." (Tesis con registro 813342 de 30 de enero de 1940). Esto es: la interpretación realizada en análisis únicamente protegía el aspecto sustantivo del principio, debido a que, en tanto no se emitiera una sentencia de fondo, condenatoria o absolutoria, estaba permitido el inicio de un procedimiento posterior, negándose de forma absoluta la vertiente procesal. Es pertinente destacar aquí que el artículo 328 del Código Nacional de Procedimientos Penales (CNPP) —y antes el artículo 304 del Código Federal de Procedimientos Penales ${ }^{5}$ (CFPP) - equipara la figura del sobreseimiento penal firme con la categoría de sentencia absolutoria, por lo cual, cuando este se decrete, el principio non bis in ídem debe operar en favor de la persona procesada, impidiendo que sea sancionada en más de una ocasión. Resulta bastante orientador

${ }^{5}$ Promulgado el 30 de agosto de 1934, en el Diario Oficial de la Federación y abrogado con la entreda en vigor del Código Nacional de Procedimientos Penales el pasado 5 de marzo de 2014. 
para lo aquí expuesto la postura del constitucionalista mexicano Burgoa (1986), para quien los conceptos de ser juzgado o haber sido juzgado (enjuiciado) necesariamente implicaba una sentencia de condena o absolución firme e irrevocable, es decir, una sentencia que no admitiera recurso alguno; por lo tanto, si no se reunían estos requisitos, a decir del autor, nada impedía que se iniciara un nuevo procedimiento en contra del ciudadano, pues no se violaba el principio en análisis (p. 659).

Ahora bien, desde la vertiente jurídica procesal-formal, tanto la vertiente sustantiva como la adjetiva de la figura jurídica del non bis in ídem colisionan cuando la sentencia emitida en un proceso no es válida, o sea, cuando es emitida por un juez incompetente y a partir de ello los órganos de impartición de justicia han interpretado el principio en estudio. Así, ha sido interpretación uniforme de los tribunales que para que un juicio resulte válido se necesita que la autoridad encargada de emitir la decisión final resulte competente para ello, como lo dispone el artículo 16 constitucional, debido a que si no lo es entonces la decisión emitida carece de validez y, por tanto, en estricto sentido y desde el punto de vista formal, el proceso también corre la misma suerte; y es a partir de este hecho -la incompetencia de la autoridad- que el principio non bis in ídem no protege en ninguna de sus vertientes al procesado. Ello tiene razón de ser, porque si la resolución ya sea de condena, absolutoria o sobreseimiento es emitida por juez competente, el principio en estudio opera, en sus dos vertientes, en favor de la persona procesada para el efecto de que ningún otro juez del Estado pueda sancionarlo por los mismos hechos que produjeron la sentencia atinente y, por lo tanto, que tampoco se inicie otro procedimiento por esta misma causa. Por el contrario, si la resolución es emitida por un juez incompetente, el proceso debe reponerse para el efecto de que lo realice un juez con la competencia necesaria para ello y, en virtud de esta circunstancia, se emita una nueva resolución, de absolución, condena o sobreseimiento; criterio que han mantenido los órganos del Poder Judicial de la Federación, en jurisprudencia como: "Artículo 23 constitucional (casos en que no se viola)" (Tesis 812750 [6] 1 $1^{\mathrm{a}}$ Sala de 7 de mayo de 1962); "Amparo directo en materia penal. Sus efectos cuando se concede al inculpado por incompetencia por razón de territorio del juez de primera instancia que lo juzgó" (jurisprudencia PC.XX. J/1 [10a.] de 14 de febrero de 2014); y "Amparo directo en materia penal. Efectos de su concesión con motivo de la incompetencia de la autoridad responsable por razón de fuero" (interrupción de la jurisprudencia 1a./j. 21/2004) (tesis 1a. XXXII/2017 (10a.) de 17 de marzo de 2017).

Como se anticipó en las tesis precedentes, la interpretación ha sido considerar que no existe violación al principio non bis in ídem ante la incompetencia del juez que emitió la resolución de condena, absolución o sobreseimiento; en virtud de la inexistencia de esta ha de ordenarse que el juez competente reponga el procedimiento a efecto de que emita una nueva resolución que determine la situación jurídica de la persona procesada; de ahí que, a pesar de existir una resolución que haya declarado la condena, absolución o sobreseimiento, en contra o a favor del procesado, declarada inexistente en virtud de la incompetencia del juez, la vertiente sustantiva del principio no está garantizada, ya que deberá emitirse una nueva resolución que reúna los requisitos de validez exigidos por la constitución y por la ley en la que se determine la condena o absolución del procesado, luego entonces, la vertiente procesal tampoco 
está garantizada, debido a que el proceso reiniciará desde el momento en que el juez incompetente haya conocido del proceso. Criterio que se ha mantenido vigente desde 1962 al resolverse el amparo directo 1071/60, que motivó la tesis con registro T812750, cuya ratio essendi es idéntica a la contradicción de tesis 1/2013 que motiva la jurisprudencia PC. XX. J/1 P (10a.) y al amparo directo 16/2016, génesis de la tesis 1a. XXXII/2017 (10a.), referidas en párrafos previos.

A efecto de manifestar un pronunciamiento con relación a esta interpretación, es importante hacer mención de que el 18 de junio de 2008 se promulgó una reforma constitucional en la que el sistema de justicia penal transitó de uno denominado tradicional a otro de tipo acusatorio y oral, en términos del artículo 20 constitucional. Asimismo, el 5 de marzo de 2014 se promulgó el CNPP, mediante el cual se unificó el proceso penal en todo el país, tanto en el fuero federal como en el local, de los que se desprende, para efectos del presente análisis, que el ministerio público conserva la investigación y, en la mayoría de los tipos penales, el ejercicio de la acción penal; sin embargo, una vez iniciado el proceso judicial, este se convierte en una parte más, dejando de ser considerado como autoridad, asumiendo los derechos y obligaciones de una parte y también se otorga a la víctima la posibilidad de nombrar a un asesor jurídico gratuito o particular, el cual defenderá sus intereses en el proceso. De igual forma, cabe resaltar la reforma constitucional en materia de Derechos Humanos (DD. HH.) promulgada el 10 de junio de 2011, en el Diario Oficial de la Federación, de la que deriva, entre otras cuestiones, la obligación de todas las autoridades del Estado Mexicano de interpretar los DD. HH. en términos de los principios de Universalidad, Interdependencia, Indivisibilidad y Progresividad, lo cual, sin lugar a dudas, impacta de forma directa en la interpretación del artículo 23 constitucional, es decir, en el contenido y alcance del principio non bis in ídem.

Por tanto, la resolución de absolución, condena o sobreseimiento emitida por un juez penal incompetente debe tener plenos efectos en favor o en contra del procesado, en términos de las vertientes sustantiva y adjetiva del principio non bis in ídem. Lo anterior, porque el juez, el ministerio público, el defensor del procesado y el asesor jurídico de la víctima o del ofendido tienen los conocimientos jurídicos para denunciar o argumentar sobre la incompetencia del juez desde el inicio del proceso; por lo que, si ninguno de ellos emite argumento alguno con relación a esta ilegalidad, debe entenderse que tácitamente se están sometiendo a la competencia del juez penal que conoce del proceso. En consecuencia, para garantizar el principio en examen en su vertiente procesal, si una persona ha sido juzgada aún por un juez incompetente, este principio debe protegerlo, debido a que la incompetencia del juez es responsabilidad absoluta del Estado, por lo que no se debe violar en perjuicio del ciudadano este principio. 


\section{TEORÍAS QUE ESTUDIAN LOS ELEMENTOS QUE DEBEN SER ANALIZADOS PARA ACTUALIZAR EL PRINCIPIO NON BIS IN ÍDEM}

Hasta aquí se ha analizado en qué consiste el principio non bis in ídem, en qué precepto constitucional está regulado en el orden jurídico mexicano, los ámbitos de aplicación y sus vertientes sustantiva y procesal; sin embargo, no menos importante resulta analizar cómo es que en la práctica los operadores jurídicos deben examinarlo para que, en su caso, se determine si nos encontramos ante la violación o no del derecho fundamental en estudio.

Primero, se debe señalar que el artículo 23 constitucional garantiza que nadie pueda ser sancionado -vertiente sustantiva- o procesado -vertiente adjetiva- por un mismo hecho, tal y como se ha expuesto. Segundo, lo importante es analizar cuándo nos encontramos ante la presencia de un mismo delito o hecho, esto sin duda es el quid del principio en estudio, pues es la presencia de dos sanciones o procesos por los mismos hechos lo que detonará la violación al principio previsto en el artículo 23 constitucional. Al respecto, Haro (2012) nos indica que la doctrina ha identificado diversas teorías que intentan analizar este fenómeno: 1 . Teoría de los elementos; 2. Mismo hecho, mismo sujeto y mismo bien jurídico; 3. Mismo delito es igual a delitos idénticos. Corriente letrística o nomen iuris; 4. De la intensión legislativa; 5. Teoría de la evidencia ex post; 6. Misma conducta; y, 7. Episodio criminal. Con relación a la “Teoría de los elementos”, Haro (2012), siguiendo a Marc Miller y Ronald Wright, refiere que esta consiste en corroborar si para acreditar la comisión de un segundo delito se requieren o no otros elementos del delito -nomen iuris ${ }^{6}$ - en comparación con aquellos necesarios para acreditar el primer delito (p. 47). Esta teoría es violatoria de los derechos fundamentales de las personas, debido a que, para que se considere que el segundo juicio no es violatorio del principio non bis in ídem, es suficiente que se analice desde otra óptica, como puede ser el análisis del dolo y la culpa. Es decir, si en un primer juicio se condena con base en responsabilidad culposa del acusado, pero con el tiempo se encuentran indicios que demuestran que actuó con dolo, esta circunstancia sería suficiente para iniciar otro proceso sin violar el principio que se analiza, debido a que lo importante para el nomen iuris es la verdadera naturaleza del hecho y no cómo es que se apreció o fue apreciada por el juzgador; por lo tanto, resulta evidente la trasgresión de los derechos fundamentales de adoptar por esta postura. En cuanto a la "Teoría letrística" o del nomen iuris, Haro (2012) señala que el segundo delito es igual que el primero solo si la acusación o ejercicio de la acción penal se hace por violación a la misma disposición jurídica relacionada con la misma conducta; por lo tanto, si con una misma conducta se cometen dos delitos o más, estos pueden seguirse en procedimientos separados e incluso sucesivos ${ }^{7}$ (p. 50). Con relación a la "Teoría de la intención legislativa", Haro (2012), siguiendo a Thomas III en Double Jeopardy. The History, the Law, sostiene que para esta no se viola el principio de non bis in ídem, si la intención legislativa explícita o implícita es que los delitos o acusaciones sean tratados de forma distinta o por separado:

\footnotetext{
6 "Nomen Iuris" es la expresión que hace referencia a un principio jurídico conocido como "primacia de la realidad". El significado viene a decir que las cosas son tal y como son y no tal y como las partes aseguran que son.

${ }^{7}$ Para más información sobre la teoría véase a Alfredo Haro Goñi, “El Non bis In Ídem en México”, año .
} 
Ahora bien, con relación a la prohibición de sanciones múltiples por un mismo delito, la jurisprudencia norteamericana sostiene que es posible evadir dicha prohibición si la legislación lo establece de manera expresa; lo anterior es sostenido con el argumento de que si la legislación establece una pena por un delito que se conforma por la comisión de un $\mathrm{X}$ número de delitos, no importa si ya fue sancionado por uno de éstos, pues la legislación quiso que aquel fuera un delito distinto y que se sancionara adicionalmente a cualquiera de los delitos menores cometidos (p. 54-55).

Se considera que esta teoría hace alusión más a un concurso real de delitos que a la protección del principio non bis in ídem -figuras jurídicas que obviamente son distintas-. Ello se estima así, porque en un mismo hecho pueden acontecer diversas conductas que actualicen o se ubiquen en diversos tipos penales, con lo cual, según nuestra legislación, cada tipo penal debe ser sancionado de forma independiente.

Para la teoría de la evidencia ex post, son las pruebas utilizadas en los procesos las que demuestran las acusaciones correspondientes; por ello, se aleja del simple estudio de los elementos correspondientes para ir más allá. A efecto de explicar esta teoría, Haro (2012) la ejemplifica con la falsificación de documentos prevista en los artículos 243, 244 y 245 del Código Penal Federal con relación al fraude contemplado en el diverso artículo 386 del mismo código, así nos dice que, para esta teoría, si con la falsificación se logra el engaño requerido por el fraude (p. 57), la conducta solo fue una y, por lo tanto, estaría prohibido un segundo proceso. No obstante, no se comparte la afirmación realizada por Haro cuando considera que se ofrece una mayor protección con relación al principio non bis in ídem. Ello, porque para solucionar el problema como el que ejemplifica el autor en cita existe la figura jurídica de la consunción o absorción. En todo caso, la protección que brinda la teoría ex post es que ante el despliegue de una conducta que actualice más de un tipo penal -concurso real de delitos- sean considerados como uno, sin embargo, esta figura jurídica es distinta a la protección que brinda el principio non bis in ídem.

La "Teoría de la misma conducta" establece que una acusación o juicio posterior quedan prohibidos si el Estado, para establecer un elemento esencial del delito a que se refiere dicha acusación, debe demostrar la realización de una conducta que constituye otro delito por el que el sujeto ya fue acusado o juzgado (Haro, 2012, p. 57). Lo que propone esta teoría, a diferencia de la teoría ex post, es que cada conducta, entendida en estricto sentido, debe ser perseguida por separado, es decir, si en un hecho la conducta desplegada por el sujeto activo actualiza más de una hipótesis delictiva -concurso real de delitos- y el sujeto activo fue procesado solo por una de ellas, no se viola el principio non bis in ídem, si el Estado demuestra que la segunda hipótesis delictiva no fue objeto del primer proceso. Por ello, para esta teoría, misma conducta ha de ser entendida en sentido estricto y no como hecho delictivo. En su obra, Haro (2012) postula la teoría del episodio criminal, en la cual plantea una definición amplia del término jurídico mismo delito, tal como sucede en la jurisprudencia norteamericana; es decir, para efectos del principio non bis in ídem, todos los delitos que pudieran actualizarse en un mismo hecho con independencia de su continuidad temporal o espacial deben ser atendidos por el Estado en una misma denuncia y su consecuente 
proceso judicial, con lo que se evita una fragmentación de acusaciones y procedimientos (p. 59-60). Sobre este diseño teórico y para no violentar el principio non bis in ídem, el Estado se encontraría en la obligación de que todos los delitos cometidos en un mismo hecho o episodio criminal deben ser denunciados en un mismo momento, así -de acuerdo con el ejemplo del autor-, si en un mismo episodio criminal se comete violación, secuestro y homicidio, el Estado deberá iniciar en un mismo momento la denuncia por los tres ilícitos y no de forma autónoma. Esta teoría implica varios problemas que la interpretación norteamericana ha intentado resolver con lo que ha denominado Balance de intereses con el que se permitirá una acusación o juicio sucesivo o posterior aun tratándose de los mismos hechos, cuando se trate de un delito no consumado, por el descubrimiento de nueva evidencia, por decisión del acusado, cuando se trate de delitos menores, delitos complejos o desacato a la autoridad judicial $^{8}$.

Finalmente, resulta de importancia la "teoría de la triple identidad", siendo esta la que siguen la mayoría de las legislaciones penales, pues sostiene que para determinar si nos encontramos en presencia del non bis in ídem se debe analizar que el sujeto activo de la conducta sea el mismo, que nos encontramos en presencia del mismo hecho, es decir la conducta desplegada por el sujeto activo y que esa conducta viola o trasgrede el mismo fundamento legal o bien jurídico tutelado. Al respecto, Clariá Olmedo (1998), quien sigue esta teoría, indica que para la tipificación de la triple identidad es necesario echar mano de las identidades clásicas de la elaboración de la cosa juzgada: persona, objeto y causa de persecución, las que deben de existir para la identidad total (p. 74). Así, indica que con relación al elemento subjetivo (eadem personam), el principio non bis in ídem sólo protege a la persona que se encuentra o se encontraba sujeta a un proceso penal; por lo tanto, no salvaguarda a aquellas personas a las que siendo copartícipes no se les ha iniciado proceso alguno. En cuanto al elemento objetivo (eadem re), Clariá Olmedo (1998) expone que:

Se atrapa al hecho en su materialidad sin atender a su significación jurídica; capta el acontecimiento y no el delito; la conducta básica imputada sin atender a las circunstancias refiere que es intrascendente el distinto encuadramiento penal; hurto o robo, lesiones graves o leves, homicidio simple o infanticidio. Tampoco interesa el grado de participación o delictuosidad o de desarrollo punible: autor o cómplice; tentativa o consumación (p. 74).

En consecuencia, por elemento objetivo debemos entender al hecho en sí mismo, con independencia de la denominación legal que se le dé en la norma, con ello, como lo señala Clariá, se atenderá a esta circunstancia, impidiendo que haya una persecución múltiple por la tipificación diversa del hecho. El quid respecto a esta teoría es el mismo fundamento legal o bien jurídico tutelado, puesto que dependerá de qué entendemos por mismo fundamento para calificar la vulneración al principio non bis in ídem. Así, para algunos autores, mismo fundamento es el resultado de aplicar para el inicio de un proceso o aplicación de una pena el mismo precepto legal, esto es, el mismo artículo de determinada legislación. Algunos otros consideran que mismo fundamento se refiere al bien jurídico tutelado, lo que significa que, con independencia

\footnotetext{
${ }^{8}$ Para mayor referencia al tema de balance de intereses, léase: “El non bis in ídem en México”, de Alfredo Haro Goñi.
} 
de la numeración del artículo, de su denominación o tipificación, a lo que se atiende es a que el hecho punible trasgreda el mismo bien jurídico tutelado para impedir su persecución y su sanción múltiple. Atendiendo a esta última aserción, Haro (2012) no comparte está clasificación, debido a que, a su decir, cuando se alude a un bien jurídico tutelado se entra al campo de la subjetividad, puesto que habrá tantos bienes jurídicos como autores que escriban al respecto. Por ejemplo, con relación al fraude procesal, indica que Cárdenas Rioseco reconoce como bien jurídico tutelado el patrimonio y la administración y procuración de justicia, en tanto que, para Hernández Romo Valencia es la correcta administración de justicia, para Zamora Pierce, el patrimonio y la Correcta procuración y administración de justicia y que Requena considera más de quince bienes jurídicos (p. 50).

En contra de esta posición, Sotomayor Acosta \& Toro Taborda (2017), siguiendo a Mercedes Pérez Manzano, sostienen que por mismo fundamento no debe entenderse mismo bien jurídico, sino la identidad de disvalor (p. 129), es decir, que con independencia del nomen iuris que le atribuya el legislador al tipo penal, el disvalor otorgado por la norma al injusto deba ser el mismo, para hablar de mismo fundamento. Por lo que al tema de análisis interesa, la teoría de la triple identidad es la que más se adapta para los fines pretendidos en el presente análisis, además, "mismo fundamento" debe entenderse como mismo disvalor, a efecto de proteger la garantía contenida en el artículo 23 constitucional.

\section{DERECHO ADMINISTRATIVO SANCIONADOR -ELECTORAL-}

El derecho administrativo sancionador es una rama del derecho de muy reciente aparición en el mundo jurídico, su mayor desarrollo se encuentra en Europa, para el caso específico de Iberoamérica, en España, debido a que la Constitución de aquel Estado desde su promulgación y hasta hoy día establece en los artículos 25 y 105 la facultad sancionadora de la que goza el Estado Español en materia administrativa, por lo que se constitucionalizó dicha facultad. A diferencia de lo que pasa con el caso español, en el texto original de la constitución mexicana no se previó ninguna disposición normativa en la que se estableciera la posibilidad del Estado de sancionar a los ciudadanos desde el ámbito administrativo. Góngora Pimentel (2008) refiere que, en el caso de nuestra nación, es con las reformas constitucionales de 1994 y 1996, en las que se establece el esquema procesal constitucional que empieza el reconocimiento del Derecho Administrativo Sancionador en la jurisprudencia9 de la SCJN. (p. 256), donde se señalan los principios de exacta aplicación de la ley, de tipicidad, aplicación de principios y garantías del derecho penal.

\footnotetext{
9 "Responsabilidades de los servidores públicos. Las sanciones administrativas previstas en la ley federal relativa también se rigen por el principio constitucional de exacta aplicación de la ley que impera en las de carácter penal, aun cuando sean de diversa naturaleza" (Tesis 2a. CLXXXIII/2001 de 29 de junio de 2001); "Tipicidad. El principio relativo, normalmente referido a la materia penal, es aplicable a las infracciones y sanciones administrativas" (Jurisprudencia P./J.100/2006 de 15 de agosto de 2006) y "Las infracciones fiscales se rigen por los principios del derecho administrativo sancionador y por las garantías del derecho penal, en lo que resulten aplicables" (Tesis $1^{\text {a }}$ XXVII/2007 de febrero de 2007).
} 
Por lo que respecta a la materia electoral, el régimen sancionador electoral tiene su origen en la Reforma Electoral publicada en el Diario Oficial de la Federación (DOF) el 22 de noviembre de 1996, con la que se dio origen al hoy denominado Procedimiento Sancionador Ordinario, y es hasta diez años después que con la resolución del expediente SUP-RAP-17/2006, por la Sala Superior del Tribunal Electoral del Poder Judicial de la Federación (SSTEPJF), que surge el Procedimiento Especial Sancionador (PES), mismo que fue acogido por la reforma constitucional de noviembre de 2007, y la legal del 14 de enero de 2008, motivo por el cual se expidió el Código Federal de Instituciones y Procedimientos Electorales (COFIPE) en el que se reguló formalmente el PES en la legislación federal (Ramírez, 2018, p. 29). No obstante, al igual que en otras ramas, el régimen sancionador electoral no tenía un marco teórico en el que sustentara su aplicación, por ello, la SSTEPJF, a través de las interpretaciones constitucionales y legales aplicadas a los casos que resolvía, implementó una doctrina de carácter jurisprudencial; así, los primeros criterios relevantes se remontan al año 2001, cuyos títulos hasta la fecha indican:

1. “Analogía y mayoría de razón. Alcances en el procedimiento administrativo sancionador electoral” (Tesis XLV/2001 de 14 de noviembre de 2001).

2. "Presunción de inocencia. Principio vigente en el procedimiento administrativo sancionador electoral” (Tesis LIX/2001 de14 de noviembre de 2001).

En 2002, la misma SSTEPJF aprobó el criterio intitulado: "Derecho administrativo sancionador electoral. Le son aplicables los principios del ius puniendi desarrollados por el derecho penal" (Tesis XLV/2002 de 27 de mayo de 2002). En él, la SSTEPJF acepta que los principios que han sido desarrollados por la doctrina y la jurisprudencia de la materia penal resultan aplicables al derecho administrativo sancionador, en virtud de que esta rama del derecho también es una manifestación del ius puniendi estatal. Por lo tanto, esa Sala siguió la teoría que indica que el Estado ha establecido dos regímenes distintos, en los que se pretende englobar la mayoría de las conductas ilícitas: el derecho penal y el derecho administrativo sancionador, de manera que indicó (tesis S3EL 045/2002):

La división del derecho punitivo del Estado en una potestad sancionadora jurisdiccional y otra administrativa, tienen su razón de ser en la naturaleza de los ilícitos que se pretenden sancionar y reprimir, pues el derecho penal tutela aquellos bienes jurídicos que el legislador ha considerado como de mayor trascendencia e importancia por constituir una agresión directa contra los valores de mayor envergadura del individuo y del Estado que son fundamentales para su existencia; en tanto que con la tipificación y sanción de las infracciones administrativas se propende generalmente a la tutela de intereses generados en el ámbito social, y tienen por finalidad hacer posible que la autoridad administrativa lleve a cabo su función, aunque coinciden, fundamentalmente, en que ambos tienen por finalidad alcanzar y preservar el bien común y la paz social.

Sin embargo, fue hasta el año 2005 que la misma SSTEPJF señaló expresamente cuáles son los principios que, en ejercicio de la potestad sancionadora del Estado, 
resultan aplicables al procedimiento administrativo sancionador a través de la jurisprudencia intitulada "Régimen administrativo sancionador electoral. Principios jurídicos aplicables" (Jurisprudencia 7/2005, de 1 de marzo de 2005), en donde se indican los siguientes principios: a) Un principio de reserva legal (lo no prohibido está permitido), así como el carácter limitado y exclusivo de sus disposiciones, esto es, sólo las normas jurídicas legislativas determinan la causa de incumplimiento o falta; b) El supuesto normativo y la sanción deben estar determinados legislativamente en forma previa a la comisión del hecho; c) La norma jurídica que prevea una falta o sanción debe estar expresada en una forma escrita (abstracta, general e impersonal), a efecto de que los destinatarios (tanto ciudadanos, como partidos políticos, agrupaciones políticas y autoridades administrativas y jurisdiccionales, en materia electoral) conozcan cuáles son las conductas ordenadas o prohibidas, así como las consecuencias jurídicas que provoca su inobservancia, lo que da vigencia a los principios constitucionales de certeza y objetividad (en este caso, como en lo expuesto en el inciso anterior, se está en presencia de la llamada garantía de tipicidad); y d) Las normas requieren una interpretación y aplicación estricta (odiosa sunt restringenda), porque debe ser el mínimo el ejercicio de ese poder correctivo estatal, siempre acotado y muy limitado, por cuanto que los requisitos para su puesta en marcha deben ser estrechos o restrictivos. De éstos se desprende implícitamente la prohibición contenida en el artículo 23 Constitucional, es decir, el impedimento de que persona alguna pueda ser juzgada dos veces por el mismo hecho; de tal manera que es aquí donde cobra relevancia lo aseverado en la primera parte del análisis, relacionada con la traducción de dicho precepto constitucional, debido a que, si el artículo 23 se interpretara de forma expresa, sería imposible que este se aplicara en el régimen administrativo sancionador, incluido el electoral, puesto que este no analiza delitos, sino una conducta que tiene la categoría de infracción.

Así, la primera vez que la SSTEPJF analizó implícitamente el principio non bis in ídem ${ }^{10}$ fue en el expediente SUP-RAP-013/200111 en el que revocó una sanción impuesta por el entonces Consejo General del Instituto Federal Electoral (IFE) al Partido de la Revolución Democrática, debido a que este instituto político ya había sido sancionado en un procedimiento previo por las mismas causas. No fue sino hasta la expedición del COFIPE, publicado el 1 de enero de 2008 (el cual abrogó a la legislación de mismo nombre publicada en 1996) que se estableció como una causa de improcedencia que los actos, hechos u omisiones, imputados a la misma persona ya hubieren sido analizados y la sentencia hubiera adquirido la categoría de cosa juzga. Dicha hipótesis de improcedencia se retomó en la Ley General de Instituciones y Procedimientos Electorales (LEGIPE) publicada el 23 de mayo de 2014. De ahí que, al reconocer que la doble incriminación está prohibida en el régimen sancionador electoral, ninguna persona sometida a este puede ser sancionada (vertiente sustantiva) o procesada (vertiente adjetiva) por las autoridades encargadas de investigar y resolver dichos

\footnotetext{
${ }^{10}$ Se destaca que fue "implícitamente" porque nunca lo refirió explícitamente, ni mucho menos refirió al artículo 23 Constitucional.

${ }^{11}$ Previo a la emisión de esta sentencia, dos años antes, ya se había sometido a consideración de la Sala Superior como motivo de agravio la violación al principio non bis in ídem, en los expedientes: SUP-RAP-012-1999, SUP-RAP-013-1999 y SUP-RAP-014-1999; no obstante, en ninguno de ellos se hizo algún pronunciamiento de fondo, sobre la aplicación o no del principio en la materia electoral.
} 
procedimientos, debido a que la garantía contenida en el artículo 23 constitucional lo protege.

Por ello, cuando la conducta u omisión de una persona es considerada como una infracción electoral y esta ha sido analizada por la autoridad encargada de resolver dichos procedimientos, absolviendo o sancionando al sujeto procesado, y la sentencia ha adquirido la firmeza necesaria para catalogarla como cosa juzgada, dicho acto u omisión - en su carácter de infracción - no podría generar un nuevo proceso o sentencia en la que se analizara de nueva cuenta, pues ello atentaría en contra del principio en análisis, lo que debería ocasionar que el Tribunal revisor impidiera el inicio de ese nuevo proceso o revocara la resolución correspondiente. De tal manera que debe resultar claro que una conducta u omisión que sea considerada infracción electoral no podrá sancionarse o procesarse dos veces dentro del régimen sancionador electoral, de la misma forma que opera en materia penal cuando dicha conducta u omisión es considerada como un delito.

\section{EL PRINCIPIO Y SU APLICACIÓN EN TRES DISTINTAS MATERIAS DEL DERECHO: PENAL, ADMINISTRATIVO SANCIONADOR -ELECTORAL- Y NULIDAD DE ELECCIONES}

En materia de nulidades electorales, con antelación a la reforma constitucional en materia político-electoral del año 2014, la legislación electoral federal (específicamente en los artículos 76, 77 y 77 Bis de la Ley General del Sistema de Medios de Impugnación en Materia Electoral [LGSMIME]), solo establecía un catálogo restringido de hipótesis de nulidad de la elección de Presidente de los Estados Unidos Mexicanos, Diputados y Senadores, a saber: a) Inelegibilidad del candidato; b) Que no se hubiere instalado el $20 \%$ de las casillas en el territorio correspondiente en el caso de diputados y senadores y del $25 \%$ en el caso de presidente de la república; y c) La nulidad del $20 \%$ de las casillas instaladas en el caso de diputados y senadores y $25 \%$ en el caso de presidente de la república. No obstante, ha sido recurrente en las determinaciones de las Salas del Tribunal Electoral del Poder Judicial de la Federación que para que una elección se considere válida debe reunir las características exigibles por la Constitución Política de los Estados Unidos Mexicanos, entre otras: 1. Que las elecciones sean libres, auténticas y periódicas; 2. Que el sufragio sea universal, libre, secreto y directo; 3. Que en el financiamiento de los partidos políticos y sus campañas electorales prevalezca el principio de equidad; 4. La organización de las elecciones a través de un organismo público y autónomo; 5 . Que la certeza, legalidad, independencia, imparcialidad, objetividad y máxima publicidad sean los principios rectores del proceso electoral; 6 . El establecimiento de condiciones de equidad para el acceso de los partidos políticos a los medios de comunicación social; 7. El control de la constitucionalidad y legalidad de los actos y resoluciones electorales; y 8. Respeto al principio laico del Estado. El incumplimiento de estas exigencias de carácter Constitucional dará lugar a lo que se ha denominado como nulidad de elección por violación a principios 
constitucionales $^{12}$, tal como lo ha establecido la SSTEPJF en su línea jurisprudencial. Aunado a esto, con la reforma constitucional de 2014, el artículo 41, base VI, dispuso de forma expresa lo siguiente:

La ley establecerá el sistema de nulidades de las elecciones federales o locales por violaciones graves, dolosas y determinantes en los siguientes casos:

a) Se exceda el gasto de campaña en un cinco por ciento del monto total autorizado;

b) Se compre o adquiera cobertura informativa o tiempos en radio y televisión fuera de los supuestos previstos en la ley;

c) Se reciban o utilicen recursos de procedencia ilícita o recursos públicos en las campañas.

Lo anterior resulta relevante porque, por primera vez desde 1996 en que se publicó el antecedente legislativo más remoto de la actual LGSMIME, se establecieron una serie de conductas que pueden provocar la nulidad de la elección; es decir, desde la propia Constitución se establecen causas -las que refieren los artículos 76, 77 y 77 Bis de la ley en cita- que dan lugar a la nulidad de una elección ya sea federal o local. Para fines del presente tema, se destaca la prevista en el inciso c) del artículo 41, base VI, de la CPEUM, que a la letra dispone: "Se reciban o utilicen recursos de procedencia ilícita o recursos públicos en las campañas”; ello, porque la conducta contenida en esta hipótesis de nulidad de elección también se encuentra tipificada como delito en los artículos 11, 14 y 15 de la Ley General de Delitos Electorales (LGDE), en los siguientes términos:

Artículo 11. Se impondrán de doscientos a cuatrocientos días multa y prisión de dos a nueve años, al servidor público que:

III. Destine, utilice o permita la utilización, de manera ilegal de fondos, bienes o servicios que tenga a su disposición, en virtud de su cargo, al apoyo o al perjuicio de un precandidato, partido político, coalición, agrupación política o candidato, sin perjuicio de las penas que puedan corresponder por el delito de peculado;

Artículo 14. Se impondrá prisión de dos a nueve años al precandidato, candidato, funcionario partidista o a los organizadores de actos de campaña que aproveche fondos, bienes o servicios en los términos de la fracción III del artículo 11 de esta Ley.

Artículo 15. Se impondrá de mil a cinco mil días multa y de cinco a quince años de prisión al que por sí o por interpósita persona realice, destine, utilice o reciba aportaciones de dinero o en especie a favor de algún precandidato, candidato, partido político, coalición o agrupación política cuando exista una prohibición legal para ello, o cuando los fondos o bienes tengan un origen ilí-

\footnotetext{
${ }^{12}$ El criterio jurisdiccional que contiene la causal de violación a principios contitucionales tuvo su origen en la sentencia SUP-JRC-604/2007, por la cual se calificó la elección del miembros del ayuntamiento de Yurécuaro, en el Estado de Michoacán, México, refrendándose en la sentencia SUP-JRC-165/2008, que anuló la elección de miembros del ayuntamiendo de Acapulco, Guerrero, México.
} 
cito, o en montos que rebasen los permitidos por la ley. La pena prevista en el párrafo anterior se aumentará hasta en una mitad más cuando la conducta se realice en apoyo de una precampaña o campaña electoral.

De la misma forma, la hipótesis de nulidad de elección es considerada una infracción electoral por la Ley General de Instituciones y Procedimientos Electorales, que refieren:

Artículo 445.

1. Constituyen infracciones de los aspirantes, precandidatos o candidatos a cargos de elección popular a la presente Ley:

b) En el caso de los aspirantes o precandidatos, solicitar o recibir recursos, en dinero o en especie, de personas no autorizadas por esta Ley;

Este último precepto legal debe leerse en correspondencia con los artículos 134 de la CPEUM y 54 de la Ley General de Partidos Políticos (LGPP), en los que se prohíbe que los servidores públicos influyan en la contienda electoral; por tanto, es evidente la existencia de una prohibición recíproca, por una parte, la del servidor público de influir en la contienda electoral y, por otra parte, la del candidato de recibirla.

Como se ha señalado en párrafos previos, parecería un concurso aparente de normas, puesto que la misma conducta no solo es regulada por el derecho penal como un delito, sino también por el procedimiento administrativo sancionador electoral al considerarla una infracción y causa de nulidad de una elección. No obstante, tal concurso aparente de normas no ocurre en nuestro sistema jurídico, debido a que son tres áreas distintas del derecho y, por ende, las soluciones que hemos referido en párrafos previos - principio de especialidad, principio de consunción o absorción y principio de subsidiaridad- no son soluciones entre las ramas del derecho que se han señalado. Lo anterior, porque entre las normas ninguna es especial sobre la otra, mucho menos una puede ser absorbida por las otras dos, consecuentemente, tampoco son subsidiarias. Abona a esta conclusión lo señalado por el Segundo Tribunal Colegiado en Materia Penal del Tercer Circuito en la tesis de título: "Concurso aparente de normas. Es inexistente cuando la misma conducta se sanciona simultáneamente en una ley como falta administrativa y en otra como delito, porque ambas, al ser de distinta naturaleza, pueden coexistir"13 (Tesis III.2o.P.139 P de marzo de 2005), en la que se consideró, para lo que al tema interesa, que al tratarse de dos ordenamientos legales - uno penal y otro administrativo- que contemplan penas y sanciones de distinta naturaleza, que si bien regulan una situación igual, lo hacen desde perspectivas distintas. Por lo que ambas sanciones pueden coexistir, surgiendo legalmente la posibilidad de que se impongan las sanciones de las dos especies; caso contrario sería si ambas legislaciones sancionaran la conducta como delito, porque entonces debería quedar excluida la norma menos específica.

\footnotetext{
${ }^{13}$ Es de suma trascendencia destacar que de acuerdo con la búsqueda que se realizó en el Semanario Judicial de la Federación no existen criterios que analicen esta circunstancia, siendo la tesis en comento, la única que fue localizada.
} 
El criterio más reciente que se localiza en el Semanario Judicial de la Federación fue el emitido el pasado 08 de junio de 2018, fecha en la que se publicó la tesis aprobada por el Cuarto Tribunal Colegiado en Materia Administrativa del Primer Circuito, denominada: "Sanciones penales y administrativas en el derecho disciplinario. Para imponer ambas es necesario que no exista identidad de sujeto, hecho y fundamento, conjuntamente, atento al principio non bis in idem" (Tesis I.40.A.114 A (10a.) de 8 de junio de 2018). Con esta tesis, se reafirma el criterio asumido por el Segundo Tribunal Colegiado en Materia Penal del Tercer Circuito, citado en párrafos previos, al indicar que:

...el derecho penal tiene como objetivo principal el promover el respeto a determinados bienes jurídicos tutelados mediante las normas como por ejemplo la vida, la propiedad, etcétera; de ahí que sancione las conductas dirigidas a lesionarlos o ponerlos en peligro. En cambio, el derecho disciplinario busca la adecuada y eficiente función pública, como garantía constitucional en favor de los gobernados, al imponer a una comunidad específica como lo son servidores y funcionarios públicos, una forma de conducta correcta, honesta, adecuada y pertinente a su encargo; de lo cual deriva que, al faltar a un deber o al cumplimiento de dicha conducta correcta, debe aplicarse la sanción disciplinaria.

De estas interpretaciones que los Tribunales de Circuito del Poder Judicial de la Federación han realizado en la décima época, con relación a la sanciones administrativas y penales y su posible impacto en el principio non bis in ídem, es de concluirse que la jurisdicción mexicana ha posibilitado la sanción en ambos regímenes jurídicos sin que se viole el principio en estudio, debido a que, en síntesis, los han considerado procedimientos autónomos, que no se excluyen unos de otros. Resulta, entonces, que en materia electoral los delitos electorales y los procedimientos administrativos sancionadores electorales también resultan procedimientos autónomos, por lo que bien se podría imponer una sanción administrativa y otra penal, sin que se lesione el principio contenido en el artículo 23 constitucional.

Desde aquí, debe dejarse ver la posible solución al problema planteado en el apartado anterior, al menos desde la línea jurisprudencial del Poder Judicial de la Federación en México, puesto que como se ha evidenciado con los criterios reseñados, los procesos y procedimientos seguidos en la vía penal y en la sancionadora, respectivamente, son considerados autónomos; por ello, cuando se inician procesos paralelos o se sancionan los mismos hechos cometidos por las mismas personas. Desde esta visión interpretativa, no podría generarse una afectación al derecho humano regulado en el principio non bis in ídem. Si bien en un primer momento resulta pertinente esta interpretación judicial, parece que no solo podemos ajustarnos a la autonomía de las áreas del derecho en las que está regulada la conducta u omisión catalogada como ilícito, ello porque las sanciones previstas en una y otra área del derecho tienen una finalidad específica, por ejemplo, en el derecho penal, bajo el sistema penal acusatorio y oral vigente en México, y en términos del artículo 20, apartado A, fracción I, de la CPEUM; los principales fines son: el esclarecimiento de los hechos, proteger al inocente, procurar que el culpable no quede impune y que los daños causados por el delito se reparen. Lo anterior significa que el sistema penal está construido con la finalidad de 
que el ilícito no quede impune, es decir, que se castigue la conducta tipificada como delito, de tal manera que el sistema penal protege bienes jurídicos esenciales para el Estado como lo son la vida, el patrimonio de la personas, la salud de la sociedad, la administración de justicia entre otros, en tanto que el régimen administrativo sancionador tiene como finalidad que las personas, principalmente servidores públicos y los particulares en su relación con la administración, cumplan con las obligaciones legales impuestas en su interactuar cotidiano.

Si bien el régimen administrativo sancionador electoral tiene como fin perseguir que se cumpla el principio de legalidad, su objetivo en un primer momento es que el proceso electoral siempre esté supeditado a que la contienda electoral se encuentre regida por el principio de igualdad entre todos los contendientes, de tal manera que tendrá como mayor sanción para los candidatos, la pérdida de su registro como tal y para los partidos políticos la pérdida de su registro como entidad de interés público. Estos fines y sanciones son distintos a las que persiguen el derecho penal y el régimen administrativo en general. Pero entonces, cuando esta misma conducta es situada como una causal de nulidad de una elección por la ley -o la constitución como en el caso Mexicano-, definitivamente se trata de un nivel distinto de sanción, y dicha sanción no corresponde con el sujeto que cometió el ilícito, puesto que en todo caso la causal de nulidad traerá como consecuencia que un acto jurídico emanado por un órgano administrativo electoral no tenga la validez y alcance para justificar que la elección de que se trate es válida. Sobre este contexto y sobre la interpretación de los Tribunales Colegiados de Circuito del Poder Judicial de la Federación, al permitirse la doble imposición de sanciones: uno sobre el procedimiento administrativo sancionador y otro en el derecho penal, se puede concluir que la declaración de nulidad de una elección por las hipótesis previstas en el artículo 41, base VI, constitucional, no viola el principio non bis in ídem, pues se trata de órdenes distintos de aplicación con fines igualmente distintos. En materia electoral, la Sala Toluca del TEPJF ha emitido un criterio similar al resolver el expediente ST-JDC-201/2020 y sus acumulados, en los que al resolver una infracción en materia electoral relacionada con violencia política en razón de género afirmó que el régimen sancionador electoral y el juicio para la protección de los derechos político-electorales del ciudadano son procedimientos que tienen finalidades y efectos diferenciados.

\section{ANÁLISIS COMPARADO: ESPAÑA EN EL CONTEXTO DE LA UNIÓN EUROPEA}

Como se explicó en el apartado anterior, en México la interpretación y jurisprudencia de los Tribunales del Poder Judicial de la Federación han sostenido la permisividad de sancionar en el ámbito administrativo y penal un mismo hecho ilícito, sobre la base de que son procedimientos autónomos que tienen una finalidad también distinta. Sin embargo, una conclusión así de definitiva para el principio en análisis no es compartida por la legislación y jurisprudencia de otras naciones como es el caso de España, en cuya legislación, en primer lugar, el principio non bis in ídem no está reconocido expresamente en su Constitución; no obstante, no puede concluirse que éste no opere 
en favor de los gobernados, puesto que sí se encuentra previsto en el Decreto-Ley de 25 de enero de 1977, en cuyo artículo segundo se dispone:

No se impondrán conjuntamente sanciones gubernativas y sanciones penales por unos mismos hechos. Cuando los actos contrarios al orden público puedan revestir caracteres de delito, las Autoridades gubernativas enviarán a la judicial competente los antecedentes necesarios y las actuaciones practicadas para que ésta proceda a su enjuiciamiento.

Con base en esta disposición legal, el Tribunal Constitucional de España, a decir de Alejandro Nieto (2008), se arrogó la facultad de constituyente positivo puesto que atribuyó al artículo 25 constitucional la prohibición non bis in ídem, aun cuando no lo prevé expresamente (p. 482). Con ello el máximo Tribunal Español a través de una interpretación judicial ha determinado que dicho principio tiene rango constitucional y, por lo tanto, opera en favor de todas las personas.

Ahora bien, lo interesante del caso español corresponde al hecho de que la disposición legal invocada establece que, ante un mismo hecho que se tipifique como delito y como infracción administrativa, la primacía para sancionar corresponderá a la jurisdicción penal, siendo la administrativa la que deba de suspender su proceso y remitir todas las constancias a la autoridad penal, a efecto de que sea esta la que sancione la conducta. Por lo que, jurisprudencialmente se ha formulado la regla general relativa a que la administración no puede actuar mientras no lo hayan hecho los tribunales penales, esto es, la imposibilidad de que los órganos de la administración lleven acabo actuaciones o procedimientos sancionadores en aquellos casos en que los mismos hechos puedan ser constitutivos de delito o faltas según el Código Penal o las leyes penales especiales, mientras la autoridad judicial no se haya pronunciado sobre ellos (Nieto A., 2008, p. 488), de ahí que existe una prevalencia de la jurisdicción penal sobre la administrativa. En esta tesitura, una vez que la jurisdicción penal resuelve una sentencia de condena, la administración queda sujeta a dicha determinación, por lo tanto, el principio non bis in ídem opera en favor de las personas, con el fin de que la administración no pueda iniciar ni resolver el asunto en sede administrativa. No obstante, si la sentencia penal es absolutoria, se permite a la administración iniciar el procedimiento, a efecto de determinar la responsabilidad respectiva. Entendido el principio non bis ídem como lo hace la jurisdicción española, es decir, la prevalencia de la sentencia penal sobre la administrativa, se vulnera el principio en estudio en su vertiente procesal cuando la sentencia en sede jurisdiccional resulta absolutoria, puesto que si una de las garantías del principio consiste en no sancionar (vertiente material o sustantiva) o iniciar algún proceso (vertiente procesal o adjetiva) por un mismo hecho, resulta que cuando el juez penal español absuelve a la persona sujeta a proceso, el principio non bis in ídem debe protegerlo en ambas vertientes para que la autoridad administrativa esté impedida para iniciar el proceso y, en su caso, sancionarlo.

Asimismo, en la práctica la fórmula prevista en el artículo segundo del Decreto-Ley del 25 de enero de 1977 no se cumple a cabalidad, en virtud de que la autoridad administrativa española no siempre remite las constancias a la autoridad jurisdiccional 
penal, lo que ha ocasionado conflictos sobre la prevalencia de la resolución emitida y, con ello, se han originado diversos criterios -por llamarlo de alguna forma- poco consistentes por parte de la jurisdicción de aquella nación, ${ }^{14}$ por lo que al caso interesa, con lo hasta aquí señalado queda claro el panorama general de cómo es que la jurisdicción española ha resuelto el problema de las sanciones en sede penal y administrativa. En este contexto resulta de especial relevancia el hecho de que España se encuentra dentro de un territorio al que se le ha denominado comunitario, es decir la Unión Europea, cuyo régimen jurídico está regulado por normas de carácter "supranacional", a las que los Estados miembros se han obligado a respetar y garantizar en cada uno de sus territorios. Así, la prohibición del bis in ídem ha sido retomada en convenios internacionales, entre ellos, los siguientes:

- El Pacto Internacional de Derechos Civiles y Políticos que en su artículo 14, numeral 7, dispone que: "Nadie podrá ser juzgado ni sancionado por un delito por el cual haya sido ya condenado o absuelto por una sentencia firme de acuerdo con la ley y el procedimiento penal de cada país.”

- En el Protocolo número 7 al Convenio Para la Protección de los Derechos Humanos y de las Libertades Fundamentales, que en su artículo 4 contiene la previsión del principio non bis in ídem, que establece:

1. Nadie podrá ser inculpado o sancionado penalmente por un órgano jurisdiccional del mismo Estado, por una infracción de la que ya hubiere sido anteriormente absuelto o condenado en virtud de sentencia definitiva conforme a la ley y al procedimiento penal de ese Estado.

2. Lo dispuesto en el párrafo anterior no impedirá la reapertura del proceso, conforme a la ley y al procedimiento penal del Estado interesado, si hechos nuevos o nuevas revelaciones o un vicio esencial en el proceso anterior pudieran afectar a la sentencia dictada.

3. No se autorizará derogación alguna del presente artículo invocando el artículo 15 del Convenio.

Para la autora Sanz Hermida (2008), en el ámbito de la Unión Europea esta prohibición también se recoge y sanciona con carácter transnacional fundamentalmente en el Convenio de Bruselas de 25 de mayo de 1987, así como en el Convenio de Aplicación del Acuerdo de Schengen (CAAS), en la Carta Europea de Derechos Fundamentales y en el Convenio relativo a la protección de los intereses financieros de la UE, del 26 de julio de 1995, y su Protocolo de 27 de septiembre de 1996 (p. 128). De manera que la aplicación del principio non bis in ídem -ne bis in ídem- en la Unión Europea depende en gran medida de los convenios internacionales y de los acuerdos basados en previsiones de este principio, esto es, solo mediante un acuerdo de cooperación internacional puede o debe aplicarse entre los estados contratantes con base en una solicitud concreta, lo que conlleva que tales normas tengan sustancialmente un carácter convencional, que implica una aplicación inter-partes. En opinión de Sanz Hermida (2008), el contenido normativo del Convenio de Bruselas ha quedado integrado

\footnotetext{
${ }_{14}$ Para mayor referencia a los criterios del Tribunal Constitucional de España, léase a Alejandro Nieto, "Derecho Administrativo Sancionador", p. 491 y siguientes.
} 
en los artículos 54 a 58 del CAAS, de modo que a través de esta vía encuentra una mayor relevancia práctica. La regulación establecida en el CAAS, como toda norma de origen convencional, en principio estaba limitada a los Estados que formaban parte integrante del mismo; sin embargo, estos preceptos a su vez fueron incorporados al Título VI del Tratado de la Unión Europea (TUE) (Tercer Pilar). De este modo, la regulación contenida en el CAAS ha quedado extendida a los Estados miembros de la Unión Europea, de ahí que haya sido calificado "como el primer convenio multilateral que establece un principio internacional non bis in ídem como un derecho individual erga omnes” (p. 129). De igual forma, la citada autora afirma que a raíz de la norma establecida en los artículos 54 a 58 del CAAS, específicamente del texto normativo del artículo 54:

...una persona que haya sido juzgada en sentencia firme por una parte contratante no podrá ser perseguida por los mismos hechos por otra parte contratante, siempre que, en caso de condena, se haya ejecutado la sanción, se esté ejecutando o no pueda ejecutarse ya según la legislación de la parte contratante donde haya tenido lugar la condena.

De esto se desprende que para la aplicación de este principio se exige una doble identidad subjetiva (misma persona) y objetiva (mismos hechos), que en términos similares es la que ha quedado analizada en el cuerpo del presente análisis. A estos presupuestos, Sanz añade uno previo, referido al tipo y naturaleza de la resolución necesaria y a los requisitos que debe observar dicha resolución (bis), así debe considerarse que el imputado ha sido juzgado en sentencia firme -absolutoria o condenatoriay cumplidas las obligaciones impuestas por esta, además de que debe ser emitida por una autoridad competente. Este último presupuesto no aplica para el caso de que la decisión sea archivar el asunto, pues tal determinación no puede equipararse con una sentencia firme.

De lo expuesto, se obtiene que la aplicación del principio en estudio en la Unión Europea requiere del reconocimiento de las sentencias judiciales entre los Estados miembros, lo que en gran parte depende de los sistemas normativos internos e implica la confianza mutua de estos mismos. ${ }^{15}$ De modo que, en la práctica, el conflicto de la jurisdicción y los problemas con el principio non bis in ídem trata de evitarse mediante prácticas de cooperación, después de lo cual las autoridades competentes puedan suspender o interrumpir sus procedimientos. En cambio, no hay ninguna obligación normativa, lo que significa que el doble enjuiciamiento no se excluye como

\footnotetext{
15 “Así pueden distinguirse diversos modelos o principios: el de la 'dual sovereignty doctrine', conforme al cual no impide una doble persecución y enjuiciamiento en dos Estados federados por los mismos hechos, contra un mismo sujeto; el principio de la toma en consideración, principio de compensación o de cómputo (taking into account/Anrechnungsprinzip), conforme al cual, cuando ha existido una condena previa penal en un Estado, la misma no impide una persecución penal y/o sancionatoria en otro Estado por los mismos hechos y contra el mismo sujeto, sino simplemente se toma en consideración la pena impuesta -y generalmente ejecutada- en la determinación, en su caso, de una nueva pena. Finalmente, el principio de agotamiento del procedimiento o principio de exclusión (Erledigunsprinzip): conforme a este modelo, no solo se prohíbe la doble sanción, sino también el doble enjuiciamiento contra un mismo sujeto por los mismos hechos" (Sanz Hermida , 2008, p. 134).
} 
tal, pues como para aplicar este principio es fundamental la existencia de una sentencia firme, lo que de forma alguna podría impedir la doble persecución de tales hechos en dos Estados diversos, pues necesariamente el segundo Estado tendría que llevar algunas diligencias a efecto de valorar la identidad de los tres presupuestos antes señalados. Otro aspecto, que resulta también relevante, es que la aplicación de este principio en la Unión Europea se limita generalmente a su aplicación en ámbito penal, lo que significa un desafío para el Tribunal de Justicia de la Unión Europea ante la concurrencia de un concurso de normas penales y administrativas sancionadoras.

\section{REFLEXIONES FINALES}

A lo largo de estas páginas, se ha tornado evidente que el principio non bis in ídem contenido en el artículo 23 de la Constitución Política de los Estados Unidos Mexicanos es una garantía para todas las personas sujetas a su protección, cuya finalidad última es que éstas no sean sancionadas o procesadas en más de una ocasión por los mismos hechos, garantía que en la práctica acarrea una serie de problemáticas en su aplicación, máxime cuando un mismo hecho es regulado por diversas áreas del derecho, como lo es la jurisdicción penal, administrativa sancionadora -electoral- $y$, en su caso, como causal de nulidad de elección. Así, los procedimientos administrativos y penales son autónomos con finalidades distintas dentro del sistema de impartición de justicia. Sin embargo, no se obvia que la posición mayoritaria de autores considera esto como una violación al mencionado principio, pues estiman que la potestad sancionadora del Estado prevista en el ius puniendi impide que pueda sancionarse a la persona en más de un procedimiento, siempre que éste sea de condena, absolutoria o de sobreseimiento.

Si bien es cierto que debe considerarse que los procedimientos administrativos y penales persiguen fines distintos, también lo es que, sólo cuando en ambos casos dicho disvalor sea el mismo, es que el principio non bis in ídem operara en favor del procesado. En este sentido, no es correcta la idea de los autores de que la garantía y protección del principio en estudio sea parcial, esto es, cuando el legislador en una norma de carácter especial permita expresamente la doble persecución e imposición de sanciones (administrativa y penal), puesto que tal postura acepta en los términos referidos por los tribunales mexicanos que una y otra rama son independientes con finalidades distintas y, por ende, autónomos. Por tal motivo, resulta imprecisa la interpretación realizada por el Tribunal Constitucional Español, quien se ha decantado formalmente por la prevalencia de la sentencia penal sobre los procedimientos administrativos, obviando la vertiente procesal o adjetiva del principio non bis in ídem cuando se trata de sentencias absolutorias penales, puesto que, a pesar de que ya se ha procesado y sentenciado en vía penal a una persona, permite un doble enjuiciamiento en vía administrativa. Con ello se admite tácitamente la autonomía de ambos procesos y se puede afirmar que la declaración de nulidad es la máxima sanción que se puede decretar, por contravenir las disposiciones. 
De esta manera, la significación de sanción es aquella por la cual se priva de sus efectos propios a un acto jurídico, en virtud de una causa existente en el momento de su celebración. Así, se tiene que en el caso de la nulidad de elección el acto que ha sido declarado nulo, es un acto de autoridad; es decir, la declaración de validez de una elección, la cual es pronunciada o emitida por la autoridad administrativa electoral. Esto significa que aun cuando el hecho que ocasiona la nulidad de una elección -tratándose de la casual de nulidad prevista en el artículo 41 base sexta inciso c)- se genera a partir de un mismo hecho y es causada por un mismo sujeto, -conducta que a su vez se encuentra prevista como un tipo penal (delito) y como un tipo administrativo (infracción)-, lo que se está validando, o no, es la declaración referida. Por ello, debe entenderse que el Procedimiento Sancionador Electoral atribuye a las conductas tipificadas como infracciones un disvalor diverso a la rama penal, la finalidad del primero consiste en proteger -junto con el sistema de medios de impugnación en materia electoral- los principios de equidad en la contienda electoral entre todos los sujetos participantes de dicho proceso y con ello hacer eficaces los principios de esta función: legalidad, objetividad, imparcialidad, independencia, certeza y máxima publicidad.

Por su parte, con la tipicidad penal lo que se valora es el injusto, es decir, la acción valorada antijurídicamente, por lo que en el injusto se encuentra el disvalor de resultado y el disvalor de la acción, de manera que no debe concebirse como una simple relación entre la voluntad de la acción y el mandato de la norma, sino que es el daño social sufrido como consecuencia por el sujeto pasivo, la comunidad y el derecho. En consecuencia, a diferencia de lo que pasa con el procedimiento administrativo sancionador y el derecho penal electoral (criterios más recientes de los Tribunales Colegiados de Circuito del Poder Judicial de la Federación), es posible la imposición de sanciones en cada una de estas ramas por ser autónomas sin que con ello se viole el principio contenido en el artículo 23 de la constitución; en materia de nulidades electorales, ni siquiera podemos estar cerca de la violación a dicho principio, porque se considera que la sanción no opera para el sujeto infractor, sino para un acto de autoridad, como lo es la declaración de validez de la elección.

En conclusión, el principio non bis in ídem no protege a quien con su actuar ocasionó la nulidad de una elección, puesto que tal determinación, si bien es considerada como una sanción, no es impuesta a dicho sujeto, sino al acto de autoridad y a la sociedad en su conjunto, quien con sus impuestos pagará la elección extraordinaria. De tal manera que, por estas causas, los procedimientos sancionadores electorales deben seguir su cauce a efecto de prevenir, perseguir y sancionar aquellas conductas que pudieran originar una nulidad de elección, puesto que esta es la razón de ser de este tipo de procedimientos y, por ello, la declaratoria de nulidad no extingue la facultad investigadora de la autoridad administrativa electoral con la finalidad de que con posterioridad se determine la responsabilidad y, en su caso, la sanción al sujeto responsable. 


\section{REFERENCIAS}

1. Burgoa, I. (1986). Las Garantías Individuales. México: Porrúa.

2. Cárdenas, R. (2005). El Principio Non Bis in Idem nadie puede ser juzgado, castigado o perseguido dos veces por el mismo hecho. México: Porrúa.

3. Clariá, J. A. (1998). Derecho Procesal penal Tomo 1. Buenos Aires: Rubinzal-Culzoni Editores.

4. Código Federal de Procedimientos Penales (CFPP). Diario Oficial de la Federación, Distrito Federal, México, 30 de agosto de 1934.

5. Código Nacional de Procedimientos Penales (CNPP). Diario Oficial de la Federación. Ciudad de México. 5 de marzo 2014.

6. Cogan Neil H. (1997) The Complete Bill of Rights: The Drafts, Debates, Sources, and Origins, Second Edition, New York: Oxford University Press.

7. Constitución Política de los Estados Unidos Mexicanos (CPEUM). Diario Oficial de la Federación. Distrito Federal, México, 5 de febrero de 1857.

8. Constitución Política de los Estados Unidos Mexicanos (CPEUM). Diario Oficial de la Federación. Distrito Federal, México, 5 de febrero de 1917.

9. Decreto-Ley 6/1977. Boletín Oficial del Estado de España del 25 de enero de 1977.

10. Estados miembros del Consejo de Europa (22 de noviembre de 1984) Protocolo número 7 al Convenio Para la Protección de los Derechos Humanos y de las Libertades Fundamentales. Recuperado de https://www.derechoshumanos.net/Convenio-Europeo-de-Derechos-Humanos-CEDH/1984-Protocolo07-ConvenioProteccionDerechos HumanosyLibertadesFundamentales.htm

11. Góngora, G. D. (2008). "El reconocimiento del recho administrativo sancionador en la jurisprudencia constitucional mexicana”, en E. Ferrer, \& A. Zaldivar (coords.) La ciencia del derecho procesal constitucional. Estudios en homenaje a Héctor Fix-Zamudio en sus cincuenta años como investigador del derecho, México: Instituto de Investigaciones Juridicas-UNAM, pp. 255-274.

12. Haro, A. (2012). El non bis in idem en México. México: Tirant lo Blanch.

13. Ley General de Delitos Electorales (LGDE). Diario Oficial de la Federación de 23 de mayo de 2014.

14. Ley General de Instituciones y Procedimientos Electorales (LGIPE) Diario Oficial de la Federación de 23 de mayo de 2014. 
15. Ley General de Partidos Políticos (LGPP). Diario Oficial de la Federación de 23 de mayo de 2014.

16. Ley General del Sistema de Medios de Impugnación en Materia Electoral (LGSMIME). Diario Oficial de la Federación de 22 de noviembre de 1996.

17. Maier J. (1999). Derecho Procesal Penal, Parte General. Tomo I: Fundamentos. 2a edición Buenos Aires, Argentina. Editores del Puerto.

18. Nieto, A. (2008). Derecho Administrativo Sancionador. Madrid: España.

19. Plenos de Circuito. Jurisprudencia PC. XX. J/1 P (10a.) de 14 de febrero de 2014. México.

20. Ramírez, Castañeda A. y Consuelo Jaimes L. M. (2018). "El Regimen Sancionador Electoral y la nulidad de elecciones”, Revista Quid Iuris, 2da. Epoca, Vo. 2, Instituto de Investigaciones Jurídicas, UNAM, pp. 24-53. Recuperado de https://revistas-colaboracion.juridicas.unam.mx/index.php/quid-iuris/article/view/37359/34267 Fecha de consulta 28 de noviembre del 2020.

21. Sanz Hermida, A. M. (2008). “Aplicación transnacional de la prohibición del bis in idem en la Unión Europea”, Revista Penal, Núm. 21, Instituto Nacional de Ciencias Penales (INACIPE), pp. 126-138. Recuperado de http://rabida.uhu.es/dspace/bitstream/handle/10272/12076/Aplicación.pdf?sequence=2 Fecha de consulta 22 de noviembre del 2020.

22. Sotomayor Acosta , J. O., \& Toro Taborda, M. (2017). "Fundamento y alcances de la prohibición de doble incliminación del Art. 8 C. P.”, Revista Nuevo Foro Penal, Vol. 13, Núm. 89, Universidad EAFIT, Medellín, pp. 121-155. Recuperado de https://publicaciones.eafit.edu.co/index.php/nuevo-foro-penal/article/view/4973 Fecha de consulta 22 de noviembre del 2020.

23. Suprema Corte de Justicia de la Nación (1 $1^{\mathrm{a}}$ Sala). Tesis 1a. XXVII/2007 ( $9^{\mathrm{a}}$ ) de febrero de 2007. México.

24. Suprema Corte de Justicia de la Nación ( $1^{\text {a }}$ Sala). Tesis $1^{\text {a }}$. XXXII/2017 $\left(10^{\mathrm{a}}\right)$ de 17 de marzo de 2017. México.

25. Suprema Corte de Justicia de la Nación ( $1^{\mathrm{a}}$ Sala). Tesis $1^{\mathrm{a}}$. XXXII/2017 $\left(10^{\mathrm{a}}\right)$ de marzo de 2017. México.

26. Suprema Corte de Justicia de la Nación ( $1^{\text {a }}$ Sala). Tesis con registro $813342\left(5^{\text {a }}\right)$ de 30 de enero de 1940. México.

27. Suprema Corte de Justicia de la Nación (1 $1^{\mathrm{a}}$ Sala). Tesis con registro 812750 (6a) $1^{\mathrm{a}}$ Sala de 7 de mayo de 1962. México. 
28. Suprema Corte de Justicia de la Nación ( $2^{\mathrm{a}}$ Sala). Tesis $1^{\mathrm{a}}$. CLXXXIII/2001 (9a) de 29 de junio de 2001. México.

29. Suprema Corte de Justicia de la Nación (Pleno). Jurisprudencia P./J.100/2006 (9ª) de 15 agosto de 2006. México.

30. Suprema Corte de Justicia de la Nación (Pleno). Jurisprudencia P./J. 84/97 ( $9^{\mathrm{a}}$ ) de 3 de noviembre de 1997. México.

31. Suprema Corte de Justicia de la Nación. ( $1^{\mathrm{a}}$ Sala) Tesis $812750\left(6^{\mathrm{a}}\right)$ de 7 de mayo de 1962. México.

32. Tribunal Electoral del Poder Judicial de la Federación (Pleno). Jurisprudencia 7/2005 (9a) de 1 de marzo de 2005. México.

33. Tribunal Electoral del Poder Judicial de la Federación (Pleno). Tesis XLV/2001 (9ª) de 14 de noviembre de 2001. México.

34. Tribunal Electoral del Poder Judicial de la Federación (Pleno). Tesis LIX/2001 (9ª) de 14 de noviembre de 2001. México.

35. Tribunal Electoral del Poder Judicial de la Federación (Pleno). Tesis XLV/2002 (9 $\left(^{\mathrm{a}}\right)$ de 27 de mayo de 2002. México.

36. Tribunal Electoral del Poder Judicial de la Federación (TEPJF) (Sala Superior) [Internet] Sentencia SUP-RAP-013/2001 de 7 de mayo de 2002 [Consultada el 15 de mayo de 2020] Recuperado de https://www.te.gob.mx/buscador/ México.

37. Tribunales Colegiados de Circuito. Tesis I.4o.A.114 A (10a.) de 8 junio de 2018. México.

38. Tribunales Colegiados de Circuito. Tesis I.1o.A.E.3 CS (10a.) de 29 abril de 2016. México.

39. Tribunales Colegiados de Circuito. Tesis III.2o.P.139 (9a) de marzo de 2005. México. 